\title{
ESCOLARIZAÇÃO DE PESSOAS COM DEFICIÊNCIA INTELECTUAL E O ENSINO DE MATEMÁTICA: TEMÁTICAS EMERGENTES PARA A FORMAÇÃO DOCENTE NA PERSPECTIVA DA EDUCAÇ̃̃O INCLUSIVA
}

\author{
SCHOOLING OF PEOPLE WITH INTELLECTUAL DISABILITIES AND THE TEACHING OF \\ MATHEMATICS: EMERGING THEMES FOR TEACHER TRAINING IN THE PERSPECTIVE OF INCLUSIVE \\ EDUCATION \\ ESCOLARIZACIÓN DE PERSONAS CON DISCAPACIDAD INTELECTUAL Y LA ENSEÑANZA DE LA \\ MATEMÁTICA: TEMAS EMERGENTES PARA LA FORMACIÓN DOCENTE DESDE LA PERSPECTIVA DE \\ LA EDUCACIÓN INCLUSIVA
}

Clarissa Haas

E-mail: cla.haas@hotmail.com

Júlia Gechelin

RESUMO

E-mail: julia.gechelinn@gmail.com

O artigo aborda o ensino de Matemática para estudantes com deficiência intelectual nos Anos Finais do Ensino Fundamental em uma escola do Rio Grande do Sul. A escola selecionada, conforme o Censo Escolar da Educação Básica (2017), apontou a maior matrícula de estudantes com deficiência intelectual na etapa de ensino investigada, dentre as escolas públicas do município. Realizaram-se entrevistas com professoras do Atendimento Educacional Especializado (AEE) e de Matemática. Constatou-se que a deficiência continua sendo vista como intrínseca ao indivíduo. No currículo para o ensino de Matemática, prevalece a redução e simplificação dos conteúdos, limitando-se à Matemática básica e às atividades de vida diária. A articulação entre as professoras do AEE e de Matemática não é uma prática regular. Conclui-se que o modo como as professoras concebem a deficiência intelectual interfere na aprendizagem desses estudantes; o planejamento articulado entre os docentes do AEE e área curricular necessita ser intencional e regular; o currículo deve primar pela acessibilidade curricular para que os estudantes com deficiência intelectual possam participar do projeto pedagógico da turma; há necessidade de novas pesquisas e investimento na formação docente no campo da Educação Matemática e da Educação Inclusiva.

PALAVRAS-CHAVE: Inclusão escolar. Ensino de Matemática. Deficiência Intelectual. Educação Especial. Acessibilidade curricular.

\section{ABSTRACT}

This paper addresses the teaching of Mathematics for students with intellectual disabilities in the final years of Elementary School in a school of Rio Grande do Sul. The selected school, according to the educational statistics of the Census of Basic Education School (2017), had a higher number of enrolled students with intellectual disabilities in the final years of Elementary School, among the public schools in the city. Interviews were conducted with teachers of Specialized Educational Services (SES) and Mathematics. It was found that the disability is still seen as intrinsic to the individual. In the curriculum for mathematics teaching, the reduction and simplification of content prevail, being limited to basic Mathematics and daily living activities. The articulation between the SES and Mathematics teachers is not a regular practice. We can infer that the way teachers conceive the intellectual deficiency interferes with the learning of these students; the articulated planning between SES teachers and the curricular area needs to be intentional and regular; the curriculum should focus on curricular accessibility so that students with intellectual disabilities can participate in the class' pedagogical project; new research and investment in teacher training in the field of Mathematics Education and Inclusive Education is needed.

KEYWORDS: School inclusion. Mathematics Teaching. Intellectual Deficiency. Special Education. Curriculum accessibility. 


\section{RESUMEN}

El artículo analiza la enseñanza de las Matemáticas a estudiantes con discapacidad intelectual en los últimos años de Educación Básica en una escuela de Rio Grande do Sul. La escuela seleccionada, de acuerdo con el Censo Escolar de Educación Básica (2017), indicó la mayor matrícula de estudiantes con discapacidad intelectual en la etapa educativa investigada entre las escuelas públicas del municipio. Se realizaron entrevistas con profesoras de Atención Educativa Especializada (AEE) y de Matemáticas. Se constató que la discapacidad sigue siendo vista como intrínseca al individuo. En el currículo para la enseñanza de las Matemáticas prevalece la reducción y simplificación de contenidos, limitándose a la matemática básica y a las actividades de la vida diaria. La articulación entre las profesoras de la AEE y las de matemáticas no es una práctica regular. Se concluye que la forma en que las profesoras conciben la discapacidad intelectual, interfiere en el aprendizaje de estos estudiantes; la planificación articulada entre los maestros de la AEE y el área curricular debe ser intencional y regular; el currículo debe sobresalir por la accesibilidad curricular para que los estudiantes con discapacidad intelectual puedan participar en el proyecto pedagógico de la clase; son necesarias nuevas investigaciones e inversión en la formación del profesorado en el campo de la educación matemática y de la educación inclusiva.

PALABRAS CLAVE: Inclusión Escolar. Enseñanza de Matemática. Discapacidad Intelectual. Educación Especial. Accesibilidad Curricular.

\section{INTRODUÇÃO}

As últimas duas décadas, no Brasil, foram de grande investimento das políticas públicas da Educação Especial na perspectiva da Educação Inclusiva. Ainda que nos últimos quatro anos (2016 a 2020) tenham surgido direcionamentos por parte do governo federal que fragilizam a diretriz da educação inclusiva (KASSAR, REBELO, 2019; STF, 2020), a escola inclusiva representa a democratização e a garantia plena do direito à educação, independente de quaisquer condições. Portanto, a defesa pela educação inclusiva envolve o reconhecimento de suas temáticas emergentes, dos desafios no contexto da prática e do consequente investimento na formação inicial e continuada docente.

Nesse sentido, entende-se que é necessário que a temática da Educação Inclusiva articule-se com todas as áreas curriculares, tais como a Matemática, repensando formas eficazes e comprometidas com o acesso, a permanência e o direito de aprendizagem dos estudantes com deficiência na escola. Logo, é importante que os docentes possam "enxergar" a individualidade de seus educandos, operando a partir de suas potencialidades e não de suas deficiências ou dificuldades.

Diante do exposto, pretende-se analisar como está ocorrendo o ensino de Matemática para estudantes com deficiência intelectual nos Anos Finais do Ensino Fundamental, com foco específico em uma escola da Rede Municipal de Ensino de Caxias do Sul, um município da região serrana do Rio Grande do Sul (RS), na qual, por meio da análise das estatísticas educacionais, constatou-se a maior presença quantitativa de estudantes com essa deficiência. $\mathrm{O}$ levantamento estatístico foi realizado em 2017, contudo, prevalece bastante atual, uma vez que as estatísticas educacionais continuam apontando a deficiência intelectual em proporcionalidade elevada mediante as demais deficiências nas escolas de educação básica a nível nacional (FREDERICO, LAPLANE, 2020). Também, no município pesquisado, Caxias do Sul, conforme estatísticas educacionais do último Censo Escolar da Educação Básica divulgado no momento de finalização deste estudo (INEP, 2020), as matrículas dos estudantes 


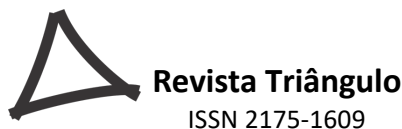

com deficiência intelectual na educação básica totalizam $63,93 \%$ do total de matrículas de estudantes identificados como público-alvo da educação especial.

Carneiro (2017) afirma que a definição de deficiência intelectual que passou a ser utilizada no Brasil foi proposta pela American Association on Intellectual and Developmental Disabilities (AAIDD) ${ }^{1}$. A entidade definiu essa deficiência da seguinte forma: "é a deficiência caracterizada por limitações no funcionamento intelectual e no comportamento adaptativo, que envolve habilidades conceituais, sociais e práticas. Essa deficiência origina-se antes dos 18 anos de idade" (AAIDD, 2010, p. 01 apud GUIMARÃES et al, 2020, p. 10). Entende-se que essa visão traz em seu bojo a possibilidade do reconhecimento que a deficiência não é uma condição intrínseca à pessoa e, sim, uma produção social, uma vez que valoriza aspectos sociais na produção diagnóstica.

Apesar disso, "[...] a deficiência intelectual ainda é vista no século XXI como uma condição individual, vivida por sujeitos que se constituem com a marca da não-aprendizagem" (CARNEIRO, 2017, p. 86). Para que se quebre esse paradigma, tornando possível a aprendizagem desses sujeitos, é necessária a compreensão de que a deficiência intelectual " [...] não está presente inicialmente em nenhum sujeito, mas vai se constituindo em decorrência do não oferecimento de relações sociais adequadas para seu desenvolvimento" (LEIJOTO; KASSAR, 2017, p. 104). Assim, cabe às escolas a promoção da quebra das barreiras que impedem o pleno desenvolvimento desses estudantes.

A Matemática está presente no cotidiano, podendo ser associada a diversas situações e atividades realizadas no dia a dia. (SILVA, SOUZA, MEDEIROS, 2020). Constatada a importância dessa área de conhecimento no âmbito escolar e social, é elementar encontrar meios para aproximá-la da realidade dos estudantes com deficiência intelectual.

Assim, faz-se necessário entender como os professores de Matemática "enxergam" os estudantes com deficiência intelectual, suas possibilidades e potencialidades, bem como a maneira com que esses estudantes interagem diante desse componente curricular para construir caminhos que aproximem professor e aluno na busca de estratégias que facilitem a aquisição de noções matemáticas fundamentais para uma vida independente por parte desses estudantes.

Cabe, ainda, mencionar que o enfoque a um grupo específico - sujeitos com deficiência intelectual - justifica-se pela complexidade que envolve a escolarização desses estudantes perante uma cultura que estigmatiza, infantiliza e incapacita as pessoas com deficiência intelectual. Reforça-se que a intenção não é defender uma pedagogia específica no ensino de Matemática para as pessoas com deficiência intelectual. Ao invés disso, pretende-se possibilitar a reflexão a respeito de modelos pedagógicos que possam atender as singularidades dos estudantes com deficiência intelectual e, simultaneamente, beneficiar a todos os estudantes da classe escolar. Desse modo, entende-se que os conhecimentos pedagógicos são basilares e fundamentais para escolarização de todos os estudantes, independente da deficiência ou outra característica ou condição que os inscreva como público da educação especial.

\footnotetext{
${ }^{1}$ A American Association on Intellectual and Developmental Disabilities - Associação Americana de Deficiência Intelectual e do Desenvolvimento (AAIDD) até 2007 era denominada American Association on Mental Retardation - Associação Americana de Deficiência Mental (AAMR).
} 
Assim, esse estudo, ao deflagrar os desafios da escolarização de estudantes com deficiência intelectual, tem o intuito de fortalecer a importância da formação inicial e continuada docente, apontando temáticas emergentes no que se refere à escolarização de estudantes com deficiência intelectual e ensino de Matemática.

\section{FOCO METODOLÓGICO}

Foram realizadas análises das entrevistas feitas em uma escola da Rede Municipal de Ensino de Caxias do Sul, RS. A escola foi apontada com base nos microdados ${ }^{2}$ do Censo Escolar da Educação Básica (INEP, 2017)³ , como a que possui maior número de estudantes com deficiência intelectual matriculados nos Anos Finais do Ensino Fundamental, dentre as escolas de educação básica do município. Os sujeitos entrevistados foram os que seguem: uma professora do Atendimento Educacional Especializado (AEE), uma professora de Matemática dos Anos Finais do Ensino Fundamental que possuem estudantes com deficiência intelectual e uma discente com essa deficiência. No presente artigo são analisadas as entrevistas realizadas com as professoras.

\section{ANÁLISE DAS ENTREVISTAS COM AS PROFESSORAS}

A Escola Municipal de Ensino Fundamental pesquisada atendia um total de 853 alunos. Desses, 58 eram estudantes com deficiência, representando aproximadamente $6,8 \%$ dos alunos atendidos pela escola. Do total de 58 alunos com deficiência, 22 eram alunos com deficiência intelectual matriculados nos Anos Finais do Ensino Fundamental, representando aproximadamente $38 \%$ do quantitativo de estudantes com deficiência. Verificou-se que a idade dos alunos com deficiência intelectual matriculados nos Anos Finais do Ensino Fundamental variava dos 11 aos 17 anos, havendo uma distorção idade-série de dois a cinco anos (INEP, 2017).

$\mathrm{Na}$ época da pesquisa de campo, a escola contava com profissionais que atuavam na rede de apoio pedagógico especializado à aprendizagem. Eram eles: quatro (04) professores responsáveis pelo AEE, além de cuidadores educacionais que auxiliam os estudantes que são público-alvo da Educação Especial. O AEE funcionava na escola desde o ano de 2011. A estrutura física da escola ainda não possibilitava acessibilidade a todos, não possuindo, por exemplo, rampas de acesso a todos os ambientes em seu interior. As professoras entrevistadas, Ana e Marina ${ }^{4}$, possuíam formação em cursos de Licenciatura e Pós-Graduação em áreas da

\footnotetext{
${ }^{2} \mathrm{O}$ acesso aos microdados foi feito a partir da utilização do software de estatística intitulado Statistical Package for the Social Sciences (SPSS).

${ }^{3}$ De acordo com o Instituto Nacional de Estudos e Pesquisas Educacionais Anísio Teixeira (INEP), "O Censo Escolar é o principal instrumento de coleta de informações da educação básica e o mais importante levantamento estatístico educacional brasileiro nessa área." (INEP, 2017). O censo é realizado anualmente, sendo que os dados de matrículas analisados nesse estudo são do ano de 2017, pois eram, durante a produção dessa investigação, os dados mais recentes publicados pelo INEP.

${ }^{4}$ Para fins de resguardar o sigilo, atribuiram-se nomes fictícios às professoras. A professora do AEE foi nomeada como Ana e a professora de Matemática como Marina.
} 
Educação Especial, sendo ambas profissionais especializadas; destaca-se ainda que possuíam em média oito (8) anos de atuação como docentes.

A seguir, abordam-se as análises das entrevistas a partir dos seguintes eixos temáticos: concepção de deficiência com foco na deficiência intelectual; organização pedagógica do AEE; acessibilidade curricular e ensino de matemática; articulação entre o AEE e a sala de aula de matemática.

\section{CONCEPÇÃO DE DEFICIÊNCIA COM FOCO NA DEFICIÊNCIA INTELECTUAL}

Com relação à concepção de deficiência, com foco na deficiência intelectual, Ana a definiu como algo que impossibilita a pessoa: "[...] uma coisa que os paralisa, eles não conseguem realmente fazer determinadas coisas [...]". Percebe-se que a deficiência é apontada como fator intrínseco à estudante, o que vem ao encontro do pensamento de Carneiro (2017) que reforça que, nos dias atuais, a deficiência intelectual ainda é considerada condição do indivíduo, sendo um fator responsável pela sua não aprendizagem.

Ana: [...] uma coisa é ter dificuldade de aprendizagem, que alguns têm, muitos têm dificuldade de aprendizagem, nós temos. Outra coisa é a deficiência intelectual, que realmente é algo que impossibilita, não é que o aluno não quer ou não faz, ele realmente não consegue. Ele chega numa barreira que vai além das forças dele [...] Eu entendo como algo que realmente atrapalha, e os deixa à margem, então por isso essa tentativa de inclusão.

Marina associou o conceito de deficiência intelectual com a maneira de ensinar, explicando a sua visão sobre o processo de ensino-aprendizagem do estudante e não a definição da deficiência.

Marina: É um processo, leva tempo, paciência. A gente tem que entender que nem sempre o aluno vai dar o que a gente espera, ele vai dar o que ele consegue; que tudo pode afetar o aprendizado, então se em casa ele não está bem, isso vai refletir na escola; se ele toma medicação ou se ele não toma, isso reflete; se ele toma medicação e deixou de tomar um dia, é outro comportamento. [...] é trabalhoso, é frustrante muitas vezes, porque a gente quer o retorno às vezes imediato [...], é gratificante, mas é bem trabalhoso.

Diante dessas explanações, nota-se que existe um conhecimento superficial da definição de deficiência intelectual, no que se refere às limitações intelectuais e comportamentais. Fica evidente que a deficiência intelectual não é vista como uma produção social pelas profissionais. Conforme traz a Declaração de Montreal, de 2004, essa deficiência é uma característica do sujeito, assim como outras características humanas, fazendo parte da diversidade e da experiência humana (MONTREAL, 2004). 


\section{ORGANIZAÇÃO PEDAGÓGICA DO AEE}

A Resolução CNE/CEB 04/2009 (BRASIL, 2009) definiu a função do AEE da seguinte forma:

[...] complementar ou suplementar a formação do aluno por meio da disponibilização de serviços, recursos de acessibilidade e estratégias que eliminem as barreiras para sua plena participação na sociedade e desenvolvimento de sua aprendizagem. (BRASIL, 2009, p. 1).

Essa definição também é reafirmada na Resolução do Conselho Municipal de Educação do município de abrangência da escola investigada (CME) no 35/2017 (CAXIAS DO SUL, 2017), em seu artigo $8^{\circ}$, parágrafo $1^{\circ}$. De acordo com a Resolução CNE/CEB 04/2009 (BRASIL, 2009), salienta-se que o profissional do AEE possui diversas atribuições para assegurar o direito à aprendizagem do estudante com deficiência. Em vista disso, enxerga-se como um ponto positivo o fato de a escola ter quatro (04) professores especializados atendendo o AEE, alcançando, supostamente, maior excelência no atendimento a esses estudantes.

Ao ser questionada sobre o aumento significativo das matrículas dos estudantes com deficiência intelectual, Ana o atribuiu a presença desses estudantes nas escolas ao direito legal. Nesse sentido, Frederico e Laplane (2020) confirmam a ampliação do público dos estudantes com deficiência intelectual nos estabelecimentos escolares:

No que se refere ao número de matrículas de alunos com deficiência intelectual, em 2018, esse público representava 67,87\% das matrículas de alunos com deficiência; assim, mais da metade do público-alvo da Educação Especial é declarada na categoria Deficiência Intelectual. (FREDERICO e LAPLANE, 2020, p. 473)

Referente ao percurso acadêmico dos estudantes com deficiência intelectual atendidos pelo AEE da escola, Ana disse que a maioria esteve durante toda a formação escolar em escola de ensino comum e que a identificação desses estudantes geralmente se inicia por meio do histórico de várias repetências ao longo da trajetória escolar. Além disso, cita que o próprio professor na sala de aula percebe no estudante maior dificuldade, fazendo um "comparativo" com os outros estudantes. Cabe ressaltar que esse "comparativo" entre os estudantes é uma prática controversa à percepção de que cada pessoa tem seu percurso singular de aprendizagem e que a avaliação deve considerar cada estudante como parâmetro de si mesmo, mapeando os seus avanços e dificuldades. Ainda, conforme a professora Ana, a partir desse primeiro olhar "comparativo", a família e a coordenação da escola são avisadas e o aluno é encaminhado para uma avaliação no AEE e depois é recomendada uma consulta médica. Ana salienta que muitas famílias acabam não levando o estudante ao médico, o que faz com que o AEE atenda muitos casos de "hipóteses de deficiência intelectual" na ausência do diagnóstico clínico.

Foi possível perceber a existência da valorização do laudo médico, balizando as práticas das docentes. Na Nota Técnica MEC/SECADI 04/2014 (BRASIL, 2014), lê-se que o diagnóstico clínico dos estudantes com deficiência não deve ser considerado indispensável, pois o AEE não é um atendimento clínico, mas sim pedagógico. O laudo médico torna-se um 

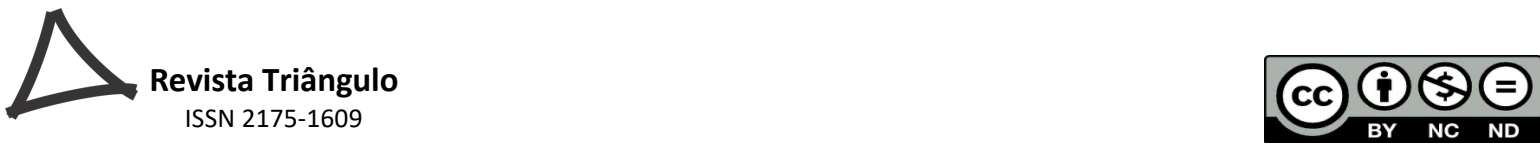

documento complementar ao Plano de AEE, se necessário, e não obrigatório. A mesma Nota afirma que:

O importante é que o direito das pessoas com deficiência à educação não poderá ser cerceado pela exigência de laudo médico. A exigência de diagnóstico clínico dos estudantes com deficiência, transtornos globais do desenvolvimento, altas habilidades/superdotação, para declará-lo, no Censo Escolar, público alvo da educação especial e, por conseguinte, garantir-lhes o atendimento de suas especificidades educacionais, denotaria imposição de barreiras ao seu acesso aos sistemas de ensino, configurando-se em discriminação e cerceamento de direito. (BRASIL, 2014, n.p.).

Apesar de ser possível constatar uma valorização do laudo médico no contexto escolar analisado, fica claro, na fala da professora, que os discentes que não possuem esse laudo e foram identificados como possíveis alunos com deficiência intelectual têm acesso ao AEE. Assim, embora aparentemente não ocorra a imposição de barreiras citada na Nota Técnica do MEC/SECADI 04/2014 (BRASIL, 2014), observa-se que o acesso ao atendimento afeta o modo como esses estudantes são nomeados, passando a serem tratados como "hipótese de defíciência intelectual". Isso também afeta a prática pedagógica que é oportunizada a esses sujeitos. Embora as professoras aleguem que há certo receio e cuidado em nomear os estudantes como sujeitos com deficiência intelectual, o modo como passam a olhar para eles condiciona as práticas ofertadas e "torna-os" sujeitos com deficiência intelectual.

Quanto à presença dos estudantes com deficiência intelectual no AEE, Ana respondeu que nem todos frequentam o atendimento e apontou algumas dificuldades para a participação deles, tais como a dificuldade dos estudantes comparecerem no contraturno das aulas. Essa ênfase à previsão do atendimento no "turno inverso" à escolarização consta no artigo $8^{\circ}$, parágrafo $3^{\circ}$ da Res. CME n 35/2017 (CAXIAS DO SUL, 2017). Ao passo que a Resolução n. 04/2009 do CNE/CEB (BRASIL, 2009), artigo $5^{\circ}$, traz a oferta do AEE no contraturno como uma possibilidade ao empregar o termo "prioritariamente", deixando em aberto para que os sistemas educacionais sejam criativos na organização do serviço e possam fazer uma leitura das necessidades a partir de seus contextos. Uma das possibilidades pode ser a proposição de ações articuladas entre os profissionais do ensino comum e especializados, sinalizado em estudos anteriores da área (HAAS, BAPTISTA, 2015, 2016).

Referente aos profissionais que apoiam a organização do AEE, Marina cita a presença do cuidador educacional que, segundo ela, auxilia em questões de locomoção e também em atividades de sala de aula. A Resolução CME no 35/2017 (CAXIAS DO SUL, 2017) define as funções do cuidador educacional, destacando-se a de auxiliar os alunos que apresentam alto grau de dependência, quanto às atividades de cuidado, higiene, alimentação e locomoção. Além disso, a resolução traz uma ampla lista de atribuições ao cuidador envolvendo atividades de acompanhamento dos estudantes com deficiência nas situações de aprendizagem escolar. (CAXIAS DO SUL, 2017). Entende-se que cabe um olhar criterioso às atribuições do cuidador que envolvem os fazeres pedagógicos, uma vez que essas funções competem ao professor da turma. Além disso, em geral, os cuidadores que atuam na rede municipal de ensino em análise têm apenas escolarização de Ensino Médio. 


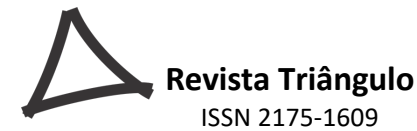

Acerca das possibilidades de articulação entre o AEE e a sala de aula comum, Ana citou a docência compartilhada, definindo-a como um momento no qual há uma tentativa "real" de que o aluno com deficiência seja inserido, de modo que os estudantes são envolvidos em uma proposta didática comum a todos. Constata-se que esse apoio não está previsto na Res. CME 35/2017 (CAXIAS DO SUL, 2017) e acontece como uma ação esporádica na escola. Marina apontou algumas dificuldades para a realização da docência compartilhada, sendo uma delas o fato de que é necessário fazer um projeto de ensino antes de realizá-la.

Marina: Então, nós temos um grande problema da docência compartilhada, porque a prioridade do AEE é os pais, depois acho que é os alunos do contraturno, e vai... E pra nós conseguirmos fazer uma docência compartilhada, a gente tem que ter um projeto antes. Então imagina a burocracia até chegar, né [...] a gente senta no horário de planejamento, eu e ela, a gente organiza algum material, agenda o periodo que eu tenho, então esse ano só foram realizadas duas. Até o ano passado era semanal, não se tinha essa obrigatoriedade de ter um projeto, propriamente. Esse projeto é feito com base no conteúdo que eu estou ensinando, a gente tenta linkar com algumas coisas [...].

Percebe-se que a docência compartilhada se torna um momento no qual podem ser criadas e colocadas em prática estratégias para que todos aprendam. Porém, é necessária uma organização maior por parte dos profissionais envolvidos, resguardando o tempo institucional de planejamento entre as docentes, para que esse momento aconteça com maior frequência e seja realmente enriquecedor.

\section{ACESSIBILIDADE CURRICULAR E O ENSINO DE MATEMÁTICA}

No que se refere à organização curricular para os estudantes com deficiência intelectual, Ana trouxe, em sua fala, que o currículo deve ser flexibilizado, conforme recomendado pelas normativas municipais.

Ana: Ele deve ser flexibilizado, é o que a lei recomenda, então o professor
precisa pensar, junto com a coordenação e a professora da sala, o quê, dentro
daquele curriculo que é montado para todas as turmas, esses estudantes de
atendimento educacional conseguem, o quê são capazes, e aí são dadas as
famosas atividades flexibilizadas, que a gente chama, que é adaptar pra ele
aquilo que ele é capaz de fazer.

Cabe destacar que Haas e Baptista $(2015 ; 2016)$ defendem o uso dos termos "acessibilidade curricular" e "adequações curriculares". Com a defesa dessa nomenclatura buscam reforçar os termos atuais empregados pelo conjunto de dispositivos legais e normativos da política de educação especial, bem como sinalizar que os termos "adaptações ou flexibilizações curriculares" comumente são associados à redução de conteúdos ou aumento do tempo destinado à tarefa. $\mathrm{Na}$ visão dos autores, esse reducionismo se aproxima da visão que associa o conceito de currículo escolar apenas a uma listagem de conteúdos. Em concordância a esse entendimento, defende-se a acessibilidade curricular como a ação pedagógica que prima por formas de tradução do conteúdo do ano escolar de pertença dos estudantes com deficiência 
em procedimentos e/ou estratégias; e, simultaneamente, considere os modos de aprender desses estudantes, a fim de engajá-los no projeto pedagógico coletivo da turma.

A respeito dos conteúdos, Ana apresentou a seguinte fala: "Eles acompanham a aula, estão em sala de aula, então em todas as disciplinas, não só em Matemática, eles acabam vendo tudo o que a turma vê. Vendo; agora, atribuindo significado, fazendo, aí não". Ao mesmo tempo, Marina trouxe que, para a maioria dos estudantes com deficiência intelectual, não são ensinados os mesmos conteúdos que para os demais estudantes. Ressalta-se que Marina atende um total de seis alunos com deficiência intelectual, sendo dois em cada sétimo ano em que dá aulas.

Marina: [...] para a maioria deles [...] eu não trabalho nada do conteúdo do sétimo ano. Hoje mesmo eu fui ali na biblioteca, eles têm uns livros pra doação então eu tenho uma coleção em casa de livros de primeiro, segundo, terceiro, quarto e quinto aninho, e conforme eles vão avançando eu vou procurando trazer mais coisas.

Em outra fala, reafirmou que é difícil trabalhar o mesmo conteúdo:

Marina: [...] eles não conseguem ver. Só conteúdo da Matemática básica [...] A gente ensina o básico pra eles sobreviverem. E tenta ensinar [...] coisas que eles vão usar pra vida. [...] no plano de trabalho que a gente tem, que nesse caso é trimestral, nós listamos todos os conteúdos dos alunos, o que a gente espera que eles atinjam, a gente destaca aquilo que a gente espera que os alunos de AEE consigam também, e a gente coloca tudo em negrito, aquilo que é específico pra esses alunos [...].

Percebe-se que as professoras balizam o direito de aprender destes estudantes nas adaptações curriculares como a retirada de conteúdos, pois acreditam que eles não vão aprender. Deste modo, ensinam conteúdos dos Anos Iniciais para estudantes que já estão nos Anos Finais do Ensino Fundamental.

Ana: Eu acho que eles conseguem avançar alguma coisa naquilo que é básico pra eles [...] que é a coisa do sistema de numeração e os cálculos matemáticos mais simples. Eles precisam entender isso, e nós temos uma preocupação também, visando o mercado de trabalho e a vida diária, de trabalhar com eles o sistema monetário, porque isso é uma necessidade pra eles, pra vida [...].

Retoma-se a necessidade de repensar um currículo comum a todos os estudantes, oferecendo experiências, por meio da utilização de diversas estratégias, que proporcionem o contato com os conteúdos do ano escolar em que o estudante está matriculado. Ao mesmo tempo em que se verifica a retirada de conteúdos, fica evidente, nas falas das professoras, que existe a preocupação quanto à aprendizagem significativa de questões de vida diária, o que, para elas, toma maior importância do que os conteúdos curriculares. Quanto a isso, Marina apresentou o seguinte posicionamento:

Marina: Quando tu vê que tu ensinou, não simplesmente Matemática, porque pra eles eu não ensino só Matemática. A gente ensina postura, a gente ensina modos, porque aqui na nossa realidade é muito complicado, então muitos não 
têm modos, muitos não sabem se portar, o linguajar, a higiene... A Ana não cansa de escovar dentes de alunos nossos com deficiência, porque eles não têm esse cuidado em casa [...] Eu sei que eles não vão sair daqui matemáticos, então a gente tem que ajudar eles a se virar [...] Eu tento ensinar caminhos, pra eles conseguirem ir em um mercado e não se perderem lá, não serem logrados no troco, conseguirem ir sozinhos... Eu trabalho muito com placas de trânsito, as cores do semáforo... Por isso que eu disse que não é só Matemática, é a vida que a gente tenta passar aqui na escola pra eles. Eu e todos os outros.

Percebe-se, por meio da fala da professora, que, ao trabalhar com as atividades de vida diária, há o envolvimento de alguns conteúdos matemáticos, como geometria plana e espacial (por exemplo, nas placas de trânsito e nas noções de localização que tenta ensinar para os alunos). Entende-se que essa relação existente não é percebida pela professora, que demonstra propor as atividades de vida diária como uma estratégia sem conexão com os conteúdos matemáticos.

Salienta-se a importância de que o professor perceba a Matemática como área de conhecimento indispensável para o dia a dia dos estudantes e se destaca a importância da vinculação entre Matemática e a vida cotidiana, uma vez que

É tarefa do professor auxiliar os estudantes a saírem da sua zona de conforto, fazendo com que busquem construir uma relação dos conteúdos a serem estudados com questões do seu cotidiano, fazendo-os se sentirem envolvidos na aprendizagem, ou instigando-os a buscarem melhores formas de compreenderem a disciplina. (SILVA; SOUSA; MEDEIROS, 2020, p.9).

As professoras relacionaram as potencialidades e dificuldades percebidas nesses estudantes com o aprendizado dos conteúdos matemáticos. As potencialidades foram resumidas ao domínio da soma, subtração e multiplicação com a consulta na tabuada; as dificuldades foram atribuídas à operação de divisão e todos os demais conteúdos matemáticos, ou, como disse a professora Marina, "[...] a partir de multiplicação, todo o resto".

Ainda, Marina apontou a construção cotidiana da aprendizagem como sendo o maior desafio no ensino de Matemática para esses estudantes:

Marina: [...] o maior desafio é esse, é o dia a dia, é a caminhada, é o acertar, o errar, é tu entender que não depende só de ti e só dele. É uma série de fatores, tudo influencia. Tem que estar no dia certo, no momento certo, ele tem que estar predisposto, aceitar aquela atividade... Muitas vezes eles não querem fazer. Às vezes tu organiza uma atividade bem legal [...] tenta mudar... Nem sempre eles querem, e às vezes eles só querem aquilo. Então é um jogo, é um jogo complicado [...].

Identifica-se, a partir das falas das professoras, que mesmo havendo uma preocupação contínua com a aprendizagem desses estudantes, os desafios são vistos como barreiras para o seu desenvolvimento, ao invés de serem explorados como possibilidades de aprendizagem. $\mathrm{O}$ foco maior se encontra nas dificuldades e não nas potencialidades de cada estudante.

As professoras citaram a necessidade da utilização de materiais concretos para favorecer a aprendizagem dos estudantes com deficiência intelectual. Também comentaram que esses alunos se esquecem com facilidade do que é trabalhado, bem como, a dependência deles de 
alguém que os auxilie. Com relação aos "esquecimentos", destaca-se o pensamento de Vieira (2017) sobre a memória, evidenciando que falta uma abordagem diferenciada, que torne significativa a aprendizagem para esses estudantes. Segundo Vieira (2017), a memória é um fator essencial para que ocorra a aprendizagem, devendo ser ativada a fim de proporcionar a aquisição de conhecimentos. Para tanto, é preciso propor diversas estratégias que oportunizem a apropriação de conteúdos, aumentando o grau de complexidade delas. Além disso, a autora salienta que a tendência do aluno é esquecer o que não faz mais sentido ou não se aplica na sua vida, conservando em sua memória somente o que é significativo para o seu dia a dia. Ainda, Vieira (2017) afirma que é necessário enxergar que as dificuldades apresentadas pelos estudantes com deficiência intelectual não diferem das apresentadas pelos demais estudantes, sendo acentuadas pelos recursos didáticos pouco eficazes.

Ao abordarem as estratégias de ensino, as professoras citaram a tentativa de trabalhar com situações-problemas e com jogos como recursos que auxiliam no entendimento dos conceitos. Na visão de Guimarães et al (2020), o problema tem caráter fundamental para o desenvolvimento humano. Os mesmos autores ressaltam: "É preciso gerar uma necessidade no estudante para despertar sua participação consciente na apropriação de conhecimentos, mediante a compreensão dos conteúdos trabalhados e das atividades propostas". (GUIMARÃES, et al, 2020, p. 16).

Quanto à utilização do jogo como recurso didático, Souza e Fonseca (2018) afirmam que o mesmo pode se tornar "[...] um estímulo à introdução e/ou desenvolvimento de conceitos de diferentes níveis de dificuldade [...]” (p. 3). Os autores também salientam a importância de um planejamento adequado para utilização do jogo como recurso, de modo que os estudantes compreendam o real objetivo da tarefa, ou seja, o propósito do jogo (SOUZA, FONSECA, 2018).

Marina também cita outras estratégias de ensino utilizadas por ela, como a montagem de figuras geométricas, folhas com desenhos para pintar, uso da calculadora, uso de jogos como bingo, dominó, quebra-cabeça, material de recorte (revistas, jornais) e registro do conteúdo do quadro. Também é importante destacar que, em várias falas, Marina cita um caderno que criou para esses estudantes com atividades diferenciadas: “[...] eu montei, pra cada um, um caderno, eu pego exercícios dos livros [...] pra tentar fazer algo diferente [...] A maioria dos livros que eu trabalho é do segundo, terceiro aninho, pros alunos que estão no sétimo" (Marina). Percebese, com isso, que existe um olhar próprio para esses estudantes, o que mostra a preocupação e dedicação de Marina para com esses alunos. Porém, questiona-se o fato do material citado ser desenvolvido especialmente e somente para os mesmos, o que os torna "diferentes" dos demais alunos. Outro aspecto questionável com relação a esse "caderno de atividades", pensado exclusivamente para esses estudantes, é o fato de ele se tornar um roteiro programado quanto ao itinerário de aprendizagem dos estudantes, com objetivos de aprendizagem rígidos.

Quando questionada sobre como é feita a avaliação dos estudantes com deficiência intelectual, Marina esclareceu que é feita por meio de um parecer descritivo, com o auxílio da professora do AEE e da coordenação.

Marina: Em dia de prova, a gente até tenta, pra eles não se sentirem excluídos, oportunizar uma prova, já que vai estar a turma inteira em silêncio, 
mas é algo que eu sei que eles não vão depender de mim, que eu vou entregar uma folhinha e eu sei que eles vão conseguir fazer... Então os colegas levam dois periodos para fazer a atividade, eu organizo algo que leve dois periodos pra eles fazerem também. Não é a mesma prova que a dos demais, nem pensar, nem pensar. E não tem nota, não existe nota. A gente faz parecer descritivo mesmo, que é feito com o auxilio da profe do AEE, com o auxílio da coordenação [...].

Fica evidente que há uma diferenciação nos instrumentos utilizados para avaliação desses sujeitos e na expressão dos resultados, uma vez que, exclusivamente para esse público, é elaborado um parecer descritivo.

\section{ARTICULAÇÃO ENTRE O AEE E A SALA DE AULA DE MATEMÁTICA}

Haas e Baptista (2016) trazem que é por meio da articulação entre o professor da sala de aula regular e o professor do AEE que se torna possível a organização de um currículo de construção de saberes para todos os estudantes, de modo que o estudante com deficiência seja incluído no trabalho coletivo.

Portanto, foi perguntado à Ana se ela interage ou participa de alguma forma do planejamento das atividades de Matemática para os estudantes com deficiência intelectual. Ana afirmou que interage com a professora de matemática, já que isso é papel dela como professora do AEE. Nesse sentido, Marina foi questionada se no planejamento das atividades para os alunos com deficiência intelectual, na disciplina de Matemática, há a interação com a professora do AEE. Em sua resposta, Marina citou que, no ano anterior, era mais dependente de Ana, mas que a outra profissional segue sendo de grande auxílio. Além disso, trouxe que Ana sempre oferece materiais complementares, como alguns livros.

Nas falas das professoras, é possível perceber que existe uma tentativa de conversa entre as profissionais e que ambas procuram agir em conjunto quanto ao planejamento de atividades, contudo nem sempre essa articulação é possível. Cabe mencionar que as professoras apresentam uma preocupação a respeito da oferta de recursos que auxiliem na aprendizagem desses estudantes. Alguns recursos são discutidos, planejados, criados e selecionados nos momentos em que é possível a interação entre as professoras. Porém, nota-se que há uma dificuldade por parte delas em encontrar maneiras de trabalhar os mesmos conteúdos com todos os estudantes; isso faz com que os conteúdos sejam selecionados para os alunos com deficiência intelectual com base naquilo que as professoras consideram que eles são capazes de realizar. Questiona-se em que medida as professoras, com esse olhar reducionista, conseguem estimular e desafiar os estudantes, pois a aprendizagem para qualquer pessoa acontece a partir de situações em que elas se sintam confrontadas, desafiadas e estimuladas a avançar além daquilo que já sabem.

Além disso, Ana foi perguntada se tem conhecimento de que as atividades de Matemática em sala de aula oferecidas para esses alunos são diferentes das oferecidas aos demais e o porquê disso.

Ana: Claro que são. Sempre. Elas têm que ser. Até pela dificuldade deles. Pela dificuldade de entendimento, de fazer, se a gente não oferecer uma coisa diferenciada, ele vai ficar ali com aquele papel, e ele vai copiar aquilo que 
ele conseguir, quando ele tá alfabetizado, se não ele não vai produzir. A professora dá outros tipos de atividades para ele, ele pode copiar, se ele quiser, a gente deixa ele a vontade, porque tem alguns, por exemplo, que têm vergonha, resistência em fazer atividades flexibilizadas. Enquanto os outros fazem um trabalho, ele recebe um trabalho voltado para as habilidades dele, aquilo que ele consegue, mesmo que acabe fugindo daquele conteúdo. Porque o professor não consegue parar, é complicado pra ele, ele tem que dar sequência àquilo que ele está fazendo em sala de aula, e aí o aluno tá ali [...].

Em sua resposta, Ana mostrou conhecimento do que acontece na sala de aula de Matemática. Marina citou que um dos alunos dela com deficiência intelectual não aceita fazer atividades flexibilizadas: “[...] ele quer aprender o que os colegas estão aprendendo [...]”. Fica evidente, nessa fala, que os próprios estudantes se sentem diferenciados com relação aos colegas. Explicou ainda que muitos deles copiam do quadro apenas para exercitar a escrita, mas que ela sempre busca proporcionar outras atividades para que eles não fiquem apenas copiando.

Nota-se, analisando e comparando as falas de ambas, que existe uma parceria entre as professoras de matemática e AEE em alguns momentos, sendo necessário um maior investimento de tempo dedicado a essa interação. Do mesmo modo, com relação à docência compartilhada, a escola precisa repensar essa prática para que ocorra de um modo efetivo e regular, que realmente corrobore para um planejamento coletivo e articulado entre as professoras, e, consequentemente, para a aprendizagem significativa dos estudantes.

Com relação ao modo como estão sendo oportunizadas as atividades aos estudantes com deficiência em sala de aula, fica claro que eles seguem percursos de aprendizagem isolados e que não se relacionam com o que está sendo proposto para toda a turma. Assim, foca-se na diferenciação dos estudantes com deficiência, consequentemente excluindo-os do projeto pedagógico da turma.

\section{CONSIDERAÇÕES FINAIS}

Considera-se de suma importância o conhecimento dos avanços no entendimento da definição de deficiência, a qual, nos documentos orientadores da política de educação especial na perspectiva da educação inclusiva, passou a ser vista como produção social, e não mais como característica intrínseca do indivíduo ou produção individual. Verificou-se que esse conhecimento ainda não faz parte dos saberes compartilhados pelas professoras, pois a deficiência continua sendo apontada como própria da pessoa, tornando-se o fator determinante para a sua não aprendizagem. $\mathrm{O}$ entendimento das professoras sobre a deficiência intelectual ainda é superficial; focam, principalmente, nas dificuldades que surgem com a deficiência. Infere-se que o aumento significativo do número de estudantes com deficiência intelectual nessa escola, e nas demais escolas da rede analisadas, possa estar relacionado a essa falta de conhecimento a respeito dessa deficiência, de modo que, nesse grupo, estariam todos os estudantes que apresentam dificuldades de aprender ou estão aquém do esperado para determinado ano escolar.

Esse entendimento se reflete na organização do currículo de Matemática, bem como nas estratégias de ensino que são oportunizadas para os estudantes com deficiência intelectual. Apurou-se que esse currículo é pensado de maneira individualizada, conforme a visão das 


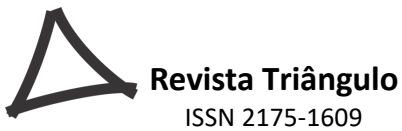

docentes sobre as possibilidades cognitivas dos estudantes. Entretanto, como a ênfase permanece voltada às dificuldades, o que ocorre é que conteúdos são retirados do currículo, permanecendo conceitos, prioritariamente, da Matemática básica, tais como, as operações de adição, subtração, multiplicação e divisão, sistema monetário e situações-problemas simples. Nessa retirada de conteúdos, conceitos matemáticos necessários para a cidadania acabam não sendo transmitidos aos alunos, como noções de álgebra e trigonometria, por exemplo. Percebese que se mantém a prática de adaptação curricular como simplificação e redução de conteúdos. Entende-se que o direcionamento pedagógico mais adequado seria a busca pela acessibilidade curricular, por meio da adequação das estratégias e recursos.

Apesar das dificuldades mencionadas, constatou-se que as professoras são atenciosas com os estudantes com deficiência intelectual e demonstram preocupação com sua aprendizagem. Ocorre que o modo como concebem a deficiência, como incapacidade, dificulta para que possam propor múltiplos caminhos de aprendizagem.

Em suma, a forma de conceber a deficiência como barreira individual para a aprendizagem afeta enormemente no planejamento das práticas pedagógicas, independente da área curricular (no caso deste estudo, a área da Matemática) a ser problematizada como conhecimento escolar aos estudantes com deficiência.

Cabe mencionar que as próprias professoras, em seu discurso, salientam que trabalham unicamente com a Matemática básica, não reconhecendo os conceitos de geometria plana e espacial nas estratégias didáticas elaboradas por elas envolvendo figuras geométricas e reconhecimento das placas de trânsito, por exemplo. Em suas falas, as professoras identificam esses conteúdos como envolvendo atividades de vida diária, e não, necessariamente, conteúdos matemáticos. Portanto, fica evidente a necessidade de estudos na área da Educação Matemática vinculados à formação inicial e continuada docente, a fim de que os professores tenham subsídios para desenvolver propostas didáticas capazes de articular o conteúdo como estratégias de ensino que promovam a acessibilidade curricular.

Orientadas por um currículo que reduz os conteúdos na área de Matemática, as professoras procuram utilizar estratégias diferenciadas e recursos diversos, como jogos e materiais concretos, para tentar garantir a aprendizagem desses estudantes, fazendo com que obtenham sucesso na realização das atividades. O que se constatou é que, apesar desse aspecto positivo, não são estimuladas as habilidades necessárias, como a capacidade de abstração e o raciocínio lógico para a aquisição de conhecimentos científicos mais elaborados.

Foi possível perceber, em alguns momentos, a existência da interação entre a professora de Matemática e a professora do AEE, no que se refere ao planejamento de atividades para os estudantes com deficiência intelectual nos Anos Finais do Ensino Fundamental. Entende-se que interação necessita ser intensificada, pois tem suma importância, uma vez que é responsabilidade de ambas as professoras a garantia da aprendizagem desses estudantes. A docência compartilhada, na escola, ocorre de forma esporádica. Deduz-se que esse dispositivo, se bem elaborado, pode colaborar para a plena inclusão dos estudantes, devendo ocorrer de forma regular. 




Destaca-se o papel da escola como espaço social que investe todos os sujeitos na condição de aprendentes capazes de acessar os conhecimentos científicos relevantes produzidos pela humanidade:

\begin{abstract}
A escola é lugar de construção de conhecimento acadêmico e, por isso, a educação escolar de pessoas com deficiência intelectual exige um posicionamento crítico e responsável de todos os educadores, pois nos força ao enfrentamento de uma realidade social que ultrapassa a questão da história de discriminação e exclusão: a questão de não sabermos ainda ensinar a esses alunos de modo que sejam, também, construtores de conhecimento científico e não apenas sujeitos de socialização. (VIEIRA, 2017, p. 524).
\end{abstract}

Por fim, fica evidente que é necessário avanços na formação inicial e continuada docente envolvendo o ensino de Matemática e a Educação Inclusiva, bem como o ensino de Matemática e a deficiência intelectual, a fim de aprofundar os conhecimentos que permeiam ambas as áreas. É essencial que a preocupação existente com a Educação Inclusiva atinja todas as áreas da Educação, inclusive a Educação Matemática, para que os professores dessa área curricular possam refletir acerca das práticas pedagógicas inclusivas.

\title{
REFERÊNCIAS
}

BRASIL. Resolução ${ }^{0}$ 4, de 2 de outubro de 2009. Diretrizes Operacionais para o Atendimento Educacional Especializado na Educação Básica, modalidade Educação Especial. Disponível em: http://portal.mec.gov.br/dmdocuments/rceb004_09.pdf. Acesso em: 7 abr. 2018.

BRASIL. Nota Técnica $n^{\circ} 4$, de 23 de janeiro de 2014. Orientação quanto a documentos comprobatórios de alunos com deficiência, transtornos globais do desenvolvimento e altas habilidades/superdotação no Censo Escolar. Disponível em:

http://portal.mec.gov.br/index.php?option=com_docman\&view=download\&alias=15898nott04-secadi-dpee-23012014\&category_slug=julho-2014-pdf\&Itemid=30192. Acesso em: 23 out. 2018.

CARNEIRO, Maria Sylvia Cardoso. Contribuições da abordagem histórico-cultural para a compreensão da deficiência intelectual como produção social. In: CAIADO; Katia Regina Moreno; BAPTISTA, Claudio Roberto; JESUS, Denise Meyrelles de. (Org.). Deficiência Mental e Deficiência Intelectual em Debate. Minas Gerais: Navegando, 2017. p. 79 - 100. Disponível em: https://www.editoranavegando.com/livro-katia. Acesso em: 23 abr. 2018.

CAXIAS DO SUL. Prefeitura Municipal. Resolução no 35, de 30 de maio de 2017. Dispõe sobre as Diretrizes para a Educação Especial no Sistema Municipal de Ensino. Disponível em: https://gcpstorage.caxias.rs.gov.br/documents/2018/04/26ca99e6-940a-4116-b1e66e51e9cea8d3.pdf . Acesso em: 17 dez. 2020.

FREDERICO, Jacqueline Caroline Costa; LAPLANE, Adriana Lia Friszman. Sobre a Participação Social da Pessoa com Deficiência Intelectual. Revista brasileira de educação especial, Bauru, v. 26, n. 3. Julho de 2020, p. 465-480. Disponível em: 
$<$ https://www.scielo.br/pdf/rbee/v26n3/1413-6538-rbee-26-03-0465.pdf $>$. Acesso em: 17 mar. 2021.

GUIMARÃES, Joice Silva Mundim et al. Deficiência Intelectual e a aprendizagem da Matemática por meio da formulação e resolução de problemas. In: OLIVEIRA, Guilherme Saramago de (org). Metodologia do Ensino de Matemática na Educação de Pessoas com Deficiência. Uberlândia, MG: FUCAMP, Navegando, 2020. p. 8 - 31. Disponível em: https://www.unifucamp.edu.br/wp-content/uploads/2020/12/LIVRO-4-met-do-ensi-dematem-pessoas-com-def.pdf. Acesso em: 17 mar. 2021.

HAAS, Clarissa; BAPTISTA, Claudio Roberto. Currículo e Educação Especial: uma relação de (re) invenção necessária a partir das imagens-narrativas dos cotidianos escolares. In: Reunião Anual da Reunião Nacional da Associação Nacional de Pós-Graduação e Pesquisa em Educação (Anped), 37., 2015, Florianópolis. Anais [...] Florianópolis, SC: Universidade Federal de Santa Catarina (UFSC), 2015. Disponível em: https://anped.org.br/sites/default/files/trabalho-gt15-4199.pdf. Acesso em: 07 abr. 2020.

HAAS, Clarissa; BAPTISTA, Claudio R. Educação Especial, currículo e Atendimento Educacional Especializado: memória e documentação dos dispositivos pedagógicos para inclusão escolar no Brasil. In: CHAVES, Vera Lucia Jacob; SOUZA, Elizeu Clementino (Org.). Documentação, memória e história da Educação no Brasil: Educação Especial, questões étnico-raciais e de gênero. Santa Catarina: Gráfica Copiart, 2016, 1 ed., v. 02, p. 117 - 136.

KASSAR, Mônica de Carvalho Magalhães; REBELO, Andressa Santos; OLIVEIRA, Regina Tereza Cestari. Embates e disputas na política nacional de Educação Especial brasileira. Educação e Pesquisa, São Paulo, v. 45, e217170, 2019. Disponível em: https://www.scielo.br/pdf/ep/v45/1517-9702-ep-45-e217170.pdf. Acesso em: 14 abr. 2020.

LEIJOTO, Camila Pereira; KASSAR, Mônica de Carvalho Magalhães. Reflexões acerca do conceito de deficiência intelectual/mental para delineamento da população escolar brasileira para registro no censo escolar. In: CAIADO; Katia Regina Moreno; BAPTISTA, Claudio Roberto; JESUS, Denise Meyrelles de. (Org.). Deficiência Mental e Deficiência Intelectual em Debate. Minas Gerais: Navegando, 2017. p. 101-122. Disponível em: https://www.editoranavegando.com/livro-katia. Acesso em: 23 abr. 2018.

MONTREAL. Declaração de Montreal sobre a Deficiência Intelectual. 2004. Disponível em: $<$ http://www.portalinclusivo.ce.gov.br/phocadownload/cartilhasdeficiente/declaracaodem ontreal.pdf $>$. Acesso em 23 abr. 2018.

SILVA, Ana Gisnayane Sousa; SOUSA, Francisco Jucivânio Félix de; MEDEIROS, Jarles Lopes de. Ensino de matemática: aspectos históricos. Pesquisa, Sociedade e

Desenvolvimento, [S. 1.] , v. 9, n. 8. Julho de 2020. Disponível em: https://rsdjournal.org/index.php/rsd/article/view/5850. Acesso em: 01 mar 2021.

SOUZA, Juliana Campos Sabino de; FONSECA, Mateus Gianni. O jogo além do jogar: O potencial do desenvolvimento de um jogo para o processo de aprendizado em matemática. In: SIPEM - Seminário Internacional de Pesquisa em Educação Matemática. Paraná, 2018. Disponível em: http://www.sbemparana.com.br/eventos/index.php/SIPEM/VII_SIPEM/paper/view/369/304. Acesso em: 17 mar. 2021.

STF. Supremo Tribunal Federal. Plenário confirma suspensão de decreto que institui a política nacional de educação especial. In: Notícias STF, 28 de dezembro de 2020. Brasília, 
$\mathrm{DF}$,

2020.

Disponível

em:

http://portal.stf.jus.br/noticias/verNoticiaDetalhe.asp?idConteudo=457869\&amp;ori=1\&gt. Acesso em: 14 abr. 2021.

VIEIRA, Scheilla de Castro Abbud. Deficiência intelectual: construção do conhecimento e o atendimento educacional especializado. 2017. Disponível em: http://ebooks.pucrs.br/edipucrs/anais/i-seminario-luso-brasileiro-de-educacaoinclusiva/assets/artigos/eixo-5/completo-8.pdf. Acesso em: 18 out. 2018. 